\title{
Congenital oesophageal stenosis caused by tracheobronchial structures in the oesophageal wall
}

\author{
N B N IBRAHIM AND R J SANDRY \\ From the Pathology Department, Frenchay Hospital, Bristol
}

ABSTRACT Congenital oesophageal stenosis caused by heterotopic: cartilage and other tracheobronchial structures in the oesophageal wall is a very rare condition. The first case was described by Frey and Duschl in 1936, and only 16 further cases have been reported since that date. We report two further cases of the anomaly. The first, like the majority described previously, was an isolated defect in an otherwise normal child. The second was associated with an oesophageal atresia with a tracheooesophageal fistula and multiple developmental anomalies of the gastrointestinal tract.

\section{Case reports}

\section{CASE 1}

A full-term male infant, delivered by forceps, was well until the age of 6 months, when he began to vomit food and mucus, particularly when solids were added to the diet. Barium swallow showed narrowing of the lower oesophagus. Oesophagoscopic dilation was followed by temporary improvement, but at the age of 14 months persistent vomiting occurred and a rapid deterioration in the child's condition necessitated more radical treatment. Oesophago-gastrectomy with oesophago-gastric anastomosis was performed. At operation there was no evidence of any abnormality of the tracheobronchial tree or of any communication between this and the oesophagus. The provisional clinical diagnosis was one of inflammatory oesophageal stenosis caused by gastrooesophageal reflux. The subsequent progress of the child was uneventful, save for the occurrence of transdiaphrag maticherniation of the colon which required operative reduction on two occasions.

\section{CASE 2}

Shortly after delivery this full-term female infant developed the typical clinical picture of oesophageal atresia with tracheo-oesophageal fistula. This was confirmed radiologically. Closure of the fistula, resection of the oesophageal stricture, and end-to-end anastomosis of the oesophagus were undertaken without delay. Postoperative recovery was uneventful, but at the age of about 18 months the child developed symptoms suggestive of duodenal ob-

Address for reprint requests: Dr NBN Ibrahim, Department of Pathology, Frenchay Hospita!, Bristol BS16 1LE. struction. Radiological investigations showed a rounded swelling compressing the second part of the duodenum, and a constant narrowing of the oesophagus, well below the site of the original anastomosis. At laparotomy a cyst was found closely related to the pyloric antrum and duodenum posteriorly. The cyst was drained into the duodenum, and the compressed duodenal segment was bypassed by gastro-enterostomy. Histological examination of the wall of the cyst showed it to be of intestinal origin, probably representing a duplication of the duodenum. Intermittent attacks of dysphagia occurred thereafter, some necessitating oesophageal dilatation. At the age of 6 years symptoms of oesophageal obstruction became more persistent and severe. After a barium investigation had shown that the lower oesophageal stricture was still present, resection of the lower oesophagus was undertaken, and an oesophago-gastric anastomosis was made at the level of the aortic arch. Colon transplant, which had been intended, was impossible because of involvement of vessels by a pancreatic cyst. A separate cyst was also present alongside the greater curvature of the stomach, and was considered to be a form of gastric duplication. No further exploration of the pancreatic or gastric cysts was undertaken.

\section{Pathological examination}

CASE 1

\section{Gross appearance}

The oesophago-gastrectomy specimen consisted of a segment of oesophagus about $4.0 \mathrm{~cm}$ long with the attached proximal part of the stomach, maximum diameter $6.0 \mathrm{~cm}$. Both externally and internally the 
oesophagus showed a fusiform narrowing: at its upper end the lumen measured $1.4 \times 0.7 \mathrm{~cm}$ whereas the diameter of the stenosed zone was only $0 \cdot 2 \mathrm{~cm}$. The whole specimen was divided into transverse blocks, which were step-sectioned.

\section{Histological examination}

The upper part of the oesophageal segment appeared normal (fig 1). In the narrow zone, however, the architecture of the wall was grossly disorganised (fig 2). The lining mucosa was largely squamous, but there was one small area of pseudo-stratified columnar epithelium resembling that of the upper respiratory tract (fig 3 ). The muscularis mucosae was slightly distorted, and the submucosa contained plates of cartilage similar to those seen in the tracheobronchial tree. The longitudinal and circular muscular laminae were replaced by an irregular and discontinuous layer of interwoven smooth muscle fibres. The normal submucosal glands were replaced by sero-mucinous glands, which were not confined to the submucosa but were scattered throughout all layers of the oesophageal wall (fig 4). Associated with the glands were some small cysts lined by columnar epithelium, sometimes pseudo-stratified and ciliated, and surrounded by a lymphocytic infiltrate in which a few follicles were seen. Below the zone of stenosis the oesophagus appeared almost normal, with only minimal submucosal fibrosis and very slight fibrous thickening of the intermuscular fascia.

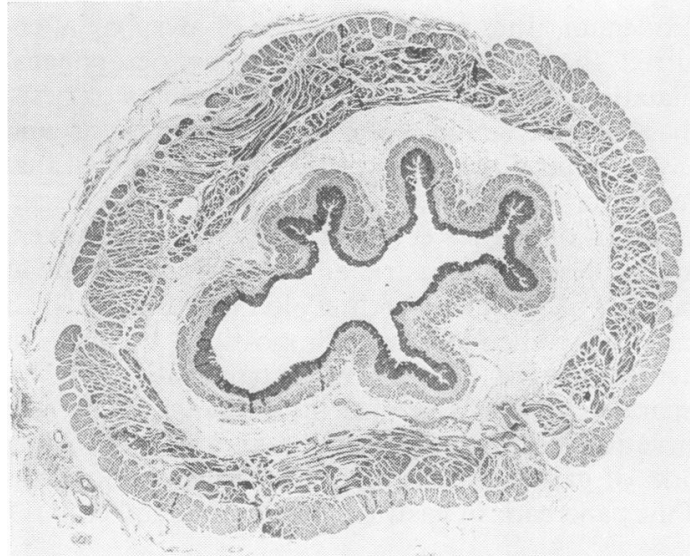

Fig 1 Transverse section through upper part of excised oesophagus. Essentially normal architecture.

Haeriatoxylir and eosin, original magnification $\times 8$.

CASE 2

Gross appearance

The specimen consisted of a segment of oesophagus

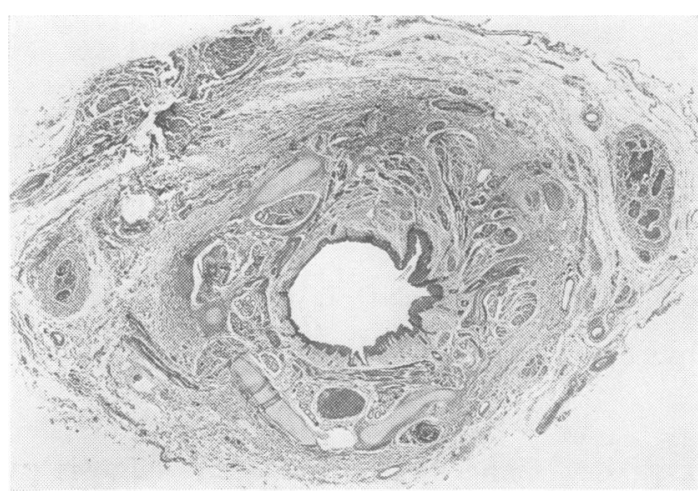

Fig 2 Transverse section at level of maximum stenosis. The plates of cartilage and the sero-mucinous glands are clearly shown. $H$ and $E$, original magnification $\times 15$.

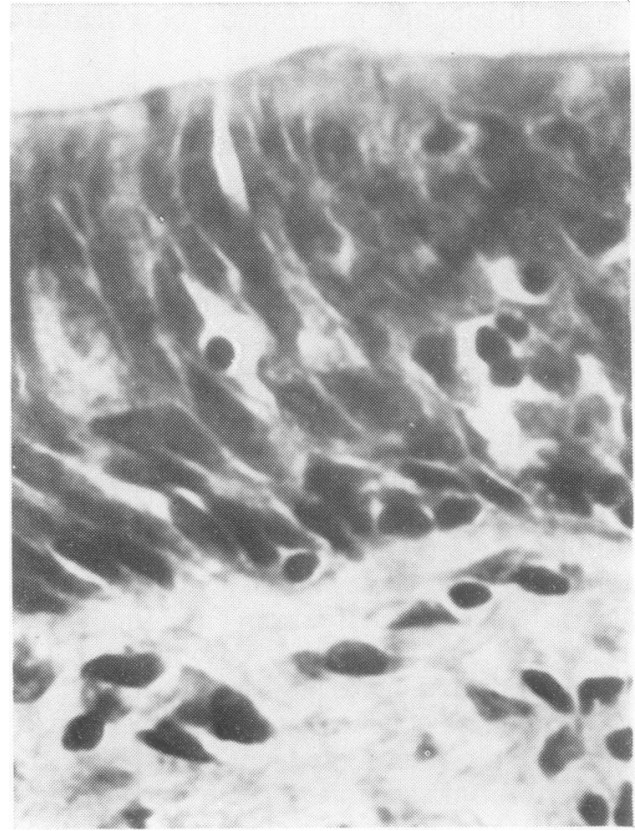

Fig 3 Small zone of pseudo-stratified columriar epithelium in the mucosa lining the nat rowed segment. $H$ and $E$, original magnification $\times 550$.

about $4.0 \mathrm{~cm}$ long, narrowed in its central part to a maximum internal diameter of $0 \cdot 3 \mathrm{~cm}$.

Histological examination
The stenotic part of the oesophagus was lined by $\frac{0}{1}$ normal stratified squamous epithelium. There was $\frac{\rho}{\mathbb{D}}$ very mild non-specific chronic inflammation in the $\stackrel{\circ}{\circ}$ lamina propria of the mucosa, and the muscularis mucosae appeared distorted in several places. There $\delta$ was gross disorganisation of the muscle layer, 


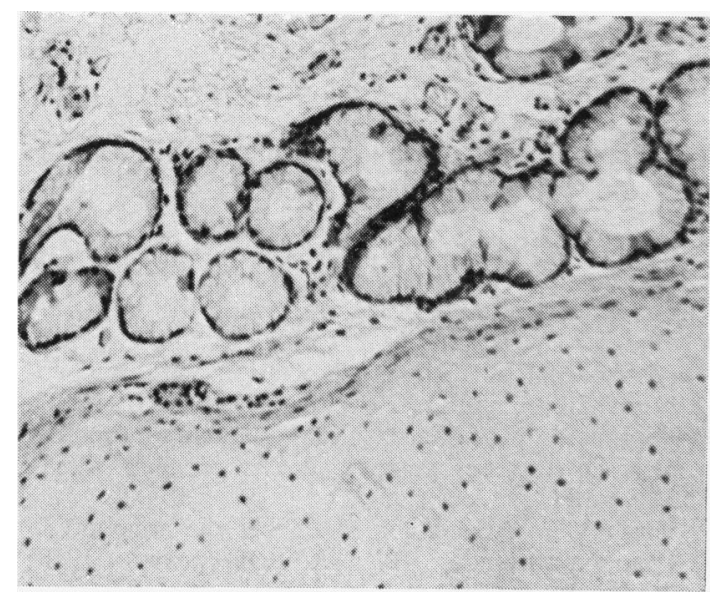

Fig 4 Sero-mucinous glands with the edge of one of the cartilaginous plates in the narrowed segment. $H$ and $E$, original magnification $\times 100$.

similar to that seen in the first case. Scattered through the full thickness of the oesophageal wall were numerous seromucinous glands, ducts from which extended to open into the lumen through the squamous epithelial lining. The outer part of the disorganised muscle layer contained a discontinuous ring of cartilage, with some scattered lymphocytes. There were no lymphoid follicles.

\section{Discussion}

In the developing embryo the tracheobronchial groove which forms the respiratory system arises as a median ventral diverticulum of the foregut at about the middle of the fourth week. The foregut caudal to the diverticulum elongates rapidly and its lumen narrows. The longitudinal grooves, which appear internally as ridges, develop on either side, in the angle between the respiratory diverticulum and the oesophagus. By fusion of the ridges the trachea becomes separated from the oesophagus, a process which begins when the embryo is about $1 \mathrm{~mm}$ long and is normally completed by the $17 \mathrm{~mm}$ stage. If the fusion of the ridges is incomplete a fistulous communication remains between the larynx or the trachea and the oesophagus. Incomplete separation may also result in the presence of heterotopic respiratory elements within the oesophageal wall in the form of cartilage and sero-mucinous glands, probably as a result of sequestration of some tracheobronchial mesenchymal cells into the oesophageal wall. The ciliated columnar epithelium present in parts of the narrowed segment in our first case (and in some of the other published cases) probably represents a localised arrest in development rather than a true heterotopia because the endodermal lining of the primitive oesophagus in the early stages of development consists of columnar cells, many of which are ciliated. On the other hand, the columnar ciliated epithelium which lines structures situated more deeply within the oesophageal wall should probably be regarded as truly heterotopic.

Congenital oesophageal stenosis associated with tracheobronchial remnants was first described in 1936 in a 19-year-old girl who died with a diagnosis of achalasia. ${ }^{1}$ Several more or less similar cases have been reported subsequently. ${ }^{2-9}$ From these relatively few cases (19 including our own), it would appear that the sex incidence is approximately equal. The main symptoms are regurgitation and vomiting, usually beginning at the time of weaning. ${ }^{9}$ In the resected specimens, the main feature is the presence of cartilage and sero-mucinous glands, similar to those seen in the tracheobronchial tree. In about half of the reported cases, the oesophagus was in part lined by columnar ciliated epithelium. The lymphoid follicles and lympho-epithelial tissue present in some cases were thought to be sufficiently bulky to contribute to the narrowing of the oesophageal lumen. ${ }^{10} 11$

In the majority of the reported cases, and in our first case, oesophageal stenosis associated with tracheobronchial structures was the only congenital anomaly found. The association of tracheooesophageal fistula with this anomaly, as in our second case, has been reported in two cases. ${ }^{7}$ Besides an oesophageal atresia with a tracheo-oseophageal fistula, our second case had multiple anomalies of the upper gastrointestinal tract. The associated oesophagitis in some of these cases was presumably caused by gastro-oesophageal reflux through a hiatus hernia, but there is no convincing evidence that the actual stenosis was the result of oesophagitis, and fibrosis which could be attributed to healed inflammation was insignificant. There seems to be no doubt that the oesophageal stricture which eventually necessitated surgical resection in both cases was caused directly by the developmental defect. The lymphoid aggregations and follicles noticed in some cases are likely to be part of the developmental anomaly rather than the result of inflammation.

Significant oesophageal narrowing of truly developmental origin, as distinct from stenosis developing as a result of reflux oesophagitis, is rare, but the diagnosis should be considered in cases where reflux cannot be clearly demonstrated, especially when there is evidence of tracheo-oesophageal fistula, present or past.

We are indebted to Mr RHR Belsey and Mr G Keen, who provided the surgical specimens and clinical details, and to $\mathrm{Mr} \mathrm{KJ}$ Dance for his invaluable 
assistance with the histological preparations and photomicrographs.

\section{References}

1 Frey EK, Duschl L. Der Kardiospasmus. Ergeb Chirurg Orthopaed 1939; 29:637-716.

2 Castleman B. Abortive congenital oesophagotracheal fistula. Case 42411. Case records of the Massachusetts General Hospital. N Engl J Med 1956; 255:707-10.

3 Kumar R. A case of congenital oesophageal stricture due to cartilaginous ring. Br J Surg 1962; 49:533-4.

4 Paulino F, Roselli A, Aprigliano F. Congenital oesophageal stricture due to tracheo-bronchial remnants. Surgery 1963; 53:547-50.

5 Ishida M, Tsuchiaa Y, Saito S, Tsunoda A. Congenital oesophageal stenosis due to tracheo-bronchial remnants. J Pediatr Surg 1969; 4:339-45.

6 Marcus PB, de Wet Lubbe JJ, Muller Botha GS. An unusual cause of congenital oesophageal stenosis. S Afr J Surg 1973; 2:145-6.

7 Deiraniya AK. Congenital oesophageal stenosis due to tracheo-bronchial remnants. Thorax 1974; 29:720-5.

8 Rose JS, Kassner EG, Jurgens KH, Farman J. ठे Congenital oesophageal strictures due to cartilaginous rings. Br J Radiol 1975; 48:16-18.

9 Ohkawa H, Takahashi H, Hoshino Y, Sato H. Lower oesophageal stenosis in association with tracheobronchial remnants. J Paediatr Surg 1975; 10:453-7.

10 Bergmann M, Charnas RM. Tracheo-bronchial rests in the oesophagus. $J$ Thorac Surg 1958; 35:97-104.

11 Spath VF, Ratzenhofer M. Ueber die angeborene Oesophagusstenose. Wien Klin Wochenschr 1959; 71:723-7. 